\title{
RUDAL (RUMAH EDUKASI PANTAI AMAL)
}

\author{
RUDAL (Educational Amal Beach House)
}

\author{
Sayupi Asri ${ }^{1}$, Sri Dewi Hernita ${ }^{2}$, Hikma Maulina ${ }^{3}$, Nurmala $\mathbf{R}^{4}$ \\ Prodi Pendidikan Matematika, Fakultas Keguruan dan Ilmu Pendidikan, Universitas Borneo Tarakan \\ Jl. Amal Lama No 1, Tarakan, Kalimantan Utara
}

\begin{abstract}
ABSTRAK
Pantai Amal merupakan wilayah pesisir di daerah Kota Tarakan, Provinsi Kalimantan Utara. Mata pencaharian terbesar di wilayah tersebut adalah nelayan dan petani rumput laut. Tidak terkecuali di Jl. Binalatung RT 14 Kelurahan Pantai Amal. Daerah tersebut juga didominasi oleh petani rumput laut. Kebanyakan masyarakat di daerah tersebut adalah pendatang dari Sulawesi dan kebanyakan masih usia sekolah. Akan tetapi, pengetahuan orang tua yang masih rendah mengenai pendidikan sehingga membiarkan anak-anak mereka untuk bekerja dan membuat banyak anak-anak yang putus sekolah demi menghasilkan uang setiap harinya. Untuk mengatasi masalah tersebut maka tim PKM-M menawarkan solusi yaitu RUDAL (Rumah Edukasi Pantai Amal) sebagai solusi untuk meningkatkan prestasi belajar generasi muda berbasis bimbingan belajar. Program ini dilakukan untuk membimbing anak-anak pantai amal binalatung agar menambah wawasan ilmu pengetahuannya selain mendapatkan ilmu dari pendidikan formal dan anak-anak yang tidak sekolah dapat mengenyam pendidikan melalui program ini meski bukan pendidikan formal. Tujuan dari program ini juga selain mengadakan bimbingan belajar, yaitu mendaftarkan anak-anak yang putus sekolah untuk mengikuti ujian paket. Melalui RUDAL diharapkan dapat meningkatkan prestasi belajar anak-anak di wilayah pesisir. Jika anak-anak di wilayah pesisir memiliki prestasi yang baik, tentunya diharapkan kelak mereka akan mengembangkan daerah tempat tinggalnya menjadi lebih baik.
\end{abstract}

Kata kunci : RUDAL, Pendidikan non-formal

\section{ABSTRACT}

Amal beach is the coastal region in Tarakan city, North Kalimantan. The largest livelihoods in the region are fisherman and seaweed farmers. Including in Jl. Binalatung RT 14 Kelurahan Pantai Amal. The area is dominated by seaweed farmers. Most of the people in the area are migrants from Sulawesi and most are still of school age. However, parents' knowledge is still low on education that allows their children to work and makes many children drop out of school to earn money every day. To overcome the problem, PKM-M team offers RUDAL solution (Rumah Edukasi Pantai Amal) as a solution to improve learning achievement of young generation based on learning guidance. This program is conducted to guide the children of balungung charity beach in order to increase their knowledge insight other than get the knowledge from formal education and the children who do not go to school can receive education through this program although not formal education. The purpose of this program is also in addition to providing tutoring, ie registering children who drop out to take the exam package. Through RUDAL is expected to improve learning achievement of children in coastal areas. If the children in the coastal areas have a good performance, of course, it is expected that they will develop a better place to live.

Keywords: RUDAL, Non formal-Education

\section{PENDAHULUAN}

Dalam UUD 1945 pasal 31 ayat 1 menyatakan bahwa setiap warga negara berhak mendapatkan pendidikan. Pendidikan diarahkan bagi seluruh warga sebagai prioritas utama agar dapat mengembangkan moral yang lebih baik yang akan memberikan pengaruh baik terhadap generasi penerus bangsa. Namun ditengah upaya peningkatan mutu pendidikan, realitas yang ada di kawasan Pantai amal tidak sebanding dengan apa yang diharapkan. Masyarakat kelurahan pantai amal sebagian bergolongan ekonomi menengah kebawah dengan mata pencaharian sebagai nelayan dan petani 

yang memiliki anak usia sekolah, saat tiba di daerah pantai amal anak-anak mereka tidak disekolahkan kembali. Hal ni dikarenakan kesulitan dalam mengurus surat pindah sekolah, kemudian mereka lebih memilih agar anak-anak mereka membantu perkejaan mereka. Dari pekerjaan yang mereka jalani, mereka juga beranggapan bahwa pendidikan adalah suatu hal yang dianggap tidak penting karena mereka berpikir kelak pada akhirnya anak serta cucu mereka juga akan meneruskan pekerjaan mereka. Sehingga pada akhirnya banyak anak- anak yang putus sekolah. Meskipun terdapat anakanak yang masih bersekolah, akan tetapi karena lingkungan sekitar yang menuntut dan menarik mereka untuk lebih banyak bekerja dan menghasilkan uang. Mereka hanya menganggap berangkat ke sekolah hanya merupakan suatu kewajiban yang harus dipenuhi tanpa peduli apakah memahami pelajaran yang dipelajari di sekolah. Hal ini membuat prestasi pelajar menurun bahkan beberapa diantaranya ada yang tidak naik kelas.

\section{METODE}

Metode pelaksanaan program kretivitas mahasiswa bidang pengabdian masyarakat bimbingan belajar rumah edukasi ini yaitu transfer ilmu dari mahasiswa Universitas Borneo Tarakan ke anak-anak di kawasan Pantai amal binalatung, Kelurahan Pantai Amal. Adapun tahapan pelaksanaan programnya dapat dibuat alur sebagai berikut:

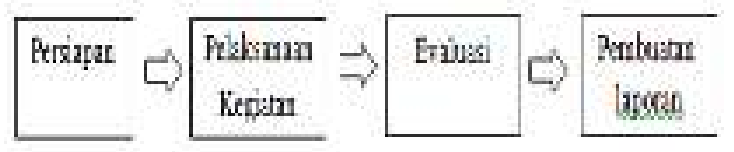

Gambar 1. Tahap Pelaksanaan Program

\section{Persiapan}

Adapun kegiatan-kegiatan yang akan dilakukan pada tahap persiapan yaitu:

a. Penetapan daerah sasaran

b. Survey beberapa tempat yang relevan untuk pelaksanaan kegiatan

$$
\text { c. Penyelesaian administrasi }
$$
perijiinan tempat dan sasaran

d. Pembuatan modul/ bahan ajar sesuai tingkatan kelas.

e. Pembuatan soal-soal latihan

f. Perbanyak modul dan soal latihan sesuai dengan jumlah peserta

2. Pelaksanaan kegiatan

Kegiatan ini telah dilaksanakan di Kelurahan Pantai Amal Rt. 14. Kegiatan bimbingan belajar dibuat semenarik mungkin, fun learning, dengan beberapa pendekatan dan metode cooperative learning. Sehingga anak-anak akan tetap merasa senang dan tidak bosan dalam mengikuti pembelajaran yang diberikan. Selain belajar mereka juga diberi pengetahuan bahwa betapa pentingnya pendidikan yang akan menjadi bekal bagi mereka di masa depan sekaligus motivasi mengenai kesuksesan dan semangat belajar.

3. Evaluasi

Evaluasi bertujuan untuk melihat perkembangan program yang dilaksanakan, mengetahui kendala yang ada, cara menanganinya, sehingga program pengabdian yang dilakukan benar-benar efektif dan maksimal. Diharapkan program ini berlangsung sampai peserta didik menghadapi Ujian Akhir Sekolah sehingga lebih terlihat berkembangan yang dialami. Pemberian ujian akhir sebagai evaluasi perkembangan dan sebagai latihan dalam menghadapi Ujian Akhir Sekolah. 
4. Pembuatan Laporan

Setelah kegiatan bimbingan belajar dilaksanakan, maka dilakukan penyusunan laporan sebagai pertanggungjawaban kegiatan pengabdian ini.

\section{HASIL DAN PEMBAHASAN}

Program RUDAL (Rumah Edukasi Pantai Amal) di Binalatung RT 14 Kelurahan Pantai Amal, Kota Tarakan sudah berjalan dengan baik. Secara keseluruhan kegiatan ini terbagi menjadi 4 bagian yaitu:

\section{a. Perencanaan}

Diawali dengan rapat koordinasi yakni menjelaskan kembali pembagian tugas kepada masing-masing anggota. Selanjutnya dilakukan penetapan daerah sasaran yang telah dilakukan pada saat proses pembuatan proposal dan menetapkan daerah Binalatung RT 14 sebagai wilayah pelaksanaan program RUDAL. Setelah proses penetapan wilayah sasaran, dilakukan survey ke beberapa tempat yang relevan di daerah tersebut yang akan digunakan untuk tempat pelaksanaan kegiatan.

Saat melakukan survey, dilakukan juga pendataan kembali peserta yang akan mengikuti kegiatan RUDAL dengan mendatangi masing-masing rumah warga di daerah tersebut. Hal ini bertujuan untuk memaksimalkan keikutsertaan peserta sekaligus memberikan penjelasan kepada orang tua di daerah tersebut betapa pentingnya kegiatan ini serta keikutsertaan anak-anak mereka pada kegiatan yang akan dilaksanakan tersebut atau sebagai bentuk sosialisasi kepada masyrakat agar mendukung anak-anak mereka dalam mengikuti kegiatan ini. Dari pendataan peserta ini, diperoleh 58 peserta didik. Jumlah ini lebih banyak dari pendataan sebelumnya saat proses pembuatan proposal ini dilakukan yang hanya sekitar 30 -an peserta. Pendataan ini juga sekaligus menanyakan kebutuhan belajar peserta didik sebagai acuan dalam proses pembuatan modul.

Setelah melakukan proses persiapan, kembali diadakan rapat koordinasi untuk memastikan hal-hal penting yang berkaitan dengan tahap persiapan selanjutnya untuk memperoleh hasil yang maksimal. Setelah itu dilakukan proses pembuatan modul berdasarkan kebutuhan peserta, sehingga dibuat 4 jenis modul yaitu pertama modul membaca, menulis, dan berhitung, kedua modul pelajaran matematika dan ketiga modul pelajaran bahasa Inggris yang berisi materi-materi dasar dan pengenalan bahasa Inggris, serta modul pelajaran IPA materi umum pelajaran IPA di tingkat SD. Di dalam modul tersebut sudah dilengkapi dengan soal-soal latihan yang akan diberikan kepada peserta didik untuk dikerjakan pada saat kegiatan bimbingan dan sebagai PR untuk para peserta. Setelah proses pembuatan modul selesai, modul diperbanyak untuk dibagikan kepada peserta.

\section{b. Pelaksanaan Kegiatan}

Kegiatan bimbingan belajar yang dilaksanakan sebanyak 8 kali pertemuan yang dilakukan setiap hari Minggu mulai pukul 15.30-17.30 WITA. Kegiatan pertama kali dilaksanakan pada tanggal 29 April 2018, dilakukan tahap perkenalan kepada msing-masing peserta didik serta perkenalan para pengajar kepada peserta didik. Selanjutnya dibentuk kelompokkelompok belajar sesuai dengan kebutuhan dan kemampuan peserta didik, sehingga terbentuk 4 kelompok belajar. Kelompok 1 adalah peserta didik yang belum bisa membaca, menulis dan berhitung terdiri dari anak-anak usia sekolah tetapi belum 
bersekolah, tidak bersekolah, dan usia TK, serta kelas 1 SD. Kelompok 2 adalah peserta didik yang sudah bisa membaca dan menulis dengan lancar terdiri dari kelas 2-3 SD. Kelompok 3 adalah peserta didik kelas 4-6 SD. Kelompok 4 adalah peserta didik SMP dan SMA. Di pertemuan selanjutnya masing-masing kelompok belajar materi yang berbeda yakni terdiri dari mata pelajaran matematika, bahasa Inggris, dan IPA.

Proses pembelajaran diselingi dengan permainan-permainan yang bertujuan agar anak-anak tidak bosan dengan kegiatan peembelajaran tersebut. Selama kegiatan bimbingan belajar, terlihat anak-anak sangat antusias dan bersemangat dalam mengikuti proses pembelajaran. Selain materi pembelajaran tidak lupa kami menyelipkan nilai-nilai moral kepada mereka seperti dalam berkata dan bertingkah laku kepada yang lebih tua dan sikap saling menyayangi sesama teman mereka.

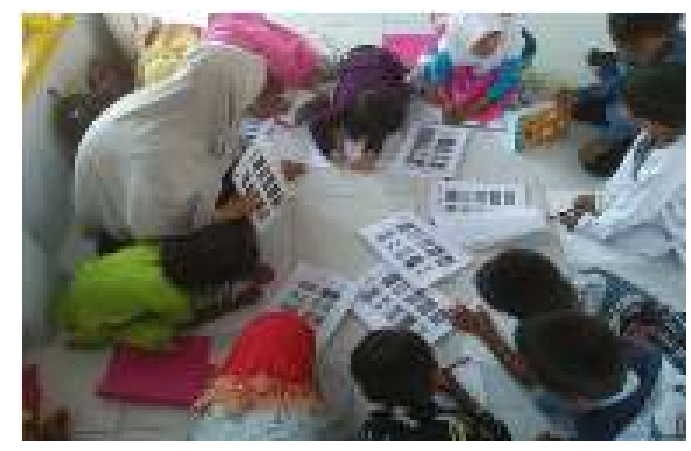

\section{Gambar 2. Kelompok 1}

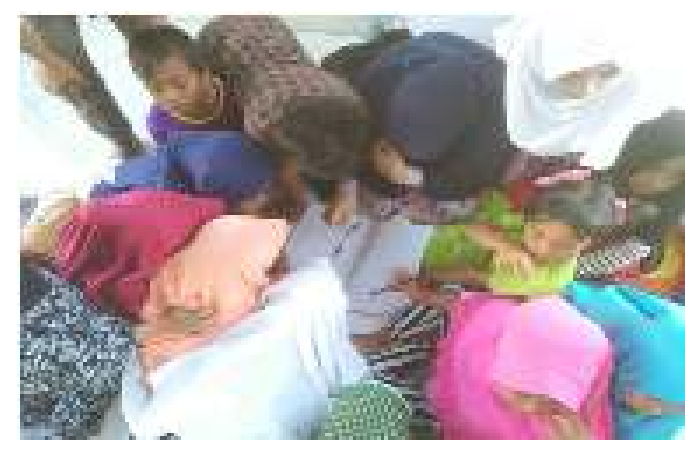

Gambar 3. Kelompok 2

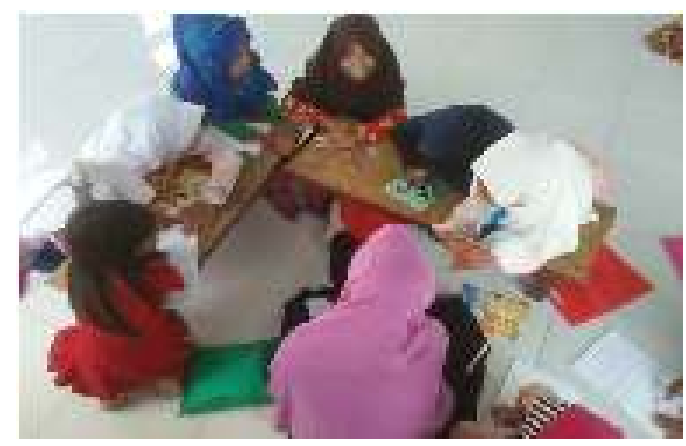

Gambar 4. Kelompok 3

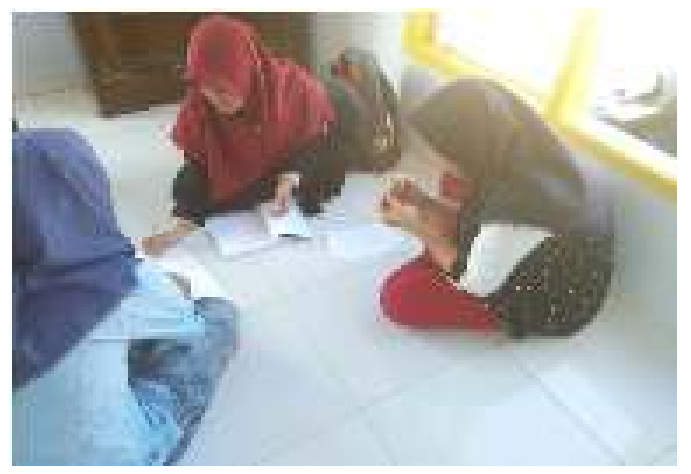

Gambar 5. Kelompok 4

\begin{tabular}{|c|c|c|c|}
\hline \multirow[t]{2}{*}{$\mathrm{No}$} & \multirow[t]{2}{*}{ Tantal. } & \multicolumn{2}{|c|}{ Ketectassian 1002} \\
\hline & & Triakand & $\begin{array}{c}\text { Bekma } \\
\text { Jenlakems }\end{array}$ \\
\hline 1. & Renetapndacélazaxan & 1005 & - \\
\hline 2. & 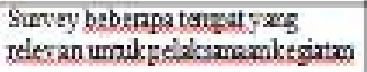 & 1005 & F \\
\hline 3 & 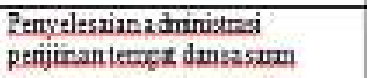 & $1003 ;$ & - \\
\hline 4 & 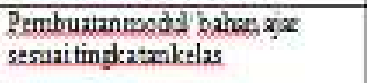 & $100 \%$ & - \\
\hline 5. & Tembuatansol-soal ation & $100 \%$ & - \\
\hline 6. & 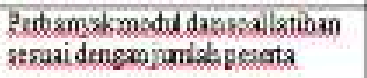 & 1002 & , \\
\hline 7 & $\begin{array}{l}\text { Pelakgamankegatan bimlingm } \\
\text { belaju }\end{array}$ & $100 \%$ & - \\
\hline 8. & 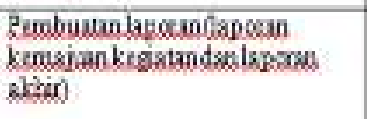 & $100 \%$ & - \\
\hline & Ketercagaian targat waran & $1003:$ & - \\
\hline
\end{tabular}

Tabel 1. Ketercapaian Target Luaran

Meskipun berdasarkan jadwal kegiatan ini telah selesai, namun kegiatan ini tetap terus dilaksanakan setiap minggunya untuk membantu meningkatkan prestasi belajar 
anak-anak pesisir yang diharapkan dapat ikut serta membantu meningkatkan kualitas pendidikan.

\section{c. Evaluasi}

Evaluasi dilakukan terhadap peningkatan prestasi belajar siswa. Selain itu juga dengan melihat peningkatan minat belajar peserta. Selama kegiatan pembelajaran ini, sudah terlihat peningkatan yang ditunjukkan oleh peserta. Mulai dari yang awalnya memiliki minat belajar rendah sekarang sudah memiliki minat belajar yang cukup tinggi terlihat dari antusias dan semngat mereka dalam mengikuti pembelajaran. Selain itu, yang sebelumnya mereka belum bisa membaca ataupun belum lancar membaca menjadi bisa membaca.

Akan tetapi yang masih perlu dievaluasi dari kegiatan ini sebagai yaitu keikutsertaan peserta lain yang masih memiliki minat yang kurang dalam mengikuti kegiatan ini akibat lingkungan mereka yang kurang mendukung.

\section{d. Pembuatan Laporan}

Laporan untuk kegiatan ini telah diselesaikan setelah kegiatan berakhir sesuai dengan jadwal yang telah direncanakan sebagai bentuk pertanggungjawaban kegiatan pengabdian ini.

\section{KESIMPULAN}

RUDAL (Rumah Edukasi Pantai Amal) merupakan salah satu kegiatan yang diadakan di daerah peissir kota Tarakan sebagai salah satu gerakan dalam rangka ikut mencerdaskan kehidupan bangsa. RUDAL sebagai solusi Meningkatkan prestasi belajar generasi muda yang berbasis bimbingan belajar. Kegiatan ini tepatnya diadakan di RT 14 Jl. Binalatung Pantai amal yang diikuti oleh anak-anak peissir baik yang masih sekolah ataupun telah putus sekolah. Kegiatan pembelajaran yang diadakan diciptakan semenarik mungkin sehingga menciptakan suasana menyenangkan bagi anak-anak. Kegiatan bimbingan belajar selalu diisi oleh semangat dan keceriaan anak-anak sehingga membuat kegiatan ini dapat berjalan dengan baik dan lancar.

\section{DAFTAR RUJUKAN}

Sigiarti, Titik \& Fina Afiana. Bimbel Koran Belajar, Bermain, dan Berkarya Untuk Bangsa. Online: http://bimbelkoran.weebly.com

Susanti, V. D \& Swasti Maharani. 2016. IbM membangun "Desa Cermat" Melalui Bimbingan Belajar dalam Meningkatkan Hasil Belajar Matematika Siswa. Jurnal Terapan Abdimas. $\quad 1(1)$ : 39-42. Online:http://download.portalgaruda. org/article 